\title{
Does endothelial dysfunction correlate with endocrinal abnormalities in patients with polycystic ovary syndrome?
}

\section{Rajani Dube}

Department of Obstetrics and Gynaecology, Ras al-Khaimah Medical and Health Sciences University, Al Qusaidat, Ras al-Khaimah, United Arab Emirates

\begin{tabular}{|c|}
\hline Access this article online \\
\hline Website: www.avicennajmed.com \\
\hline DOI: 10.4103/2231-0770.191445 \\
\hline Quick Response Code: \\
\hline
\end{tabular}

ABSTRACT
To study and critically analyze the published evidence on correlation of hormonal abnormalities
and endothelial dysfunction (ED) in polycystic ovary syndrome (PCOS) through a systematic
review. The databases including MEDLINE, PubMed, Up-To-Date, and Science Direct
were searched using Medical subject handling terms and free text term keywords such as
endocrine abnormalities in PCOS, ED assessment in PCOS, ED in combination with insulin
resistance (IR), hyperandrogenism (HA), increased free testosterone, free androgen index (FAI),
gonadotrophin levels, luteinizing hormone (LH), prolactin, estrogen, adipocytokines to search
trials, and observational studies published from January 1987 to September 2015 . Authors of
original studies were contacted for additional data when necessary. PCOS increases the risk
of cardiovascular disease in women. ED, which is a reliable indicator of cardiovascular risk in
general population, is seen in most (but not all) women with PCOS. IR, seen in 70\% patients
with PCOS, is associated with ED in these women, but patients can have normal endothelial
function even in the presence of IR. Free testosterone and FAl are consistently associated
with ED, but endothelial function can be normal despite HA. Estradiol (not estrone) appears
to be protective against ED though estrone is the predominant estrogen produced in PCOS.
Increased levels of adipocytokines (visfatin) are promising in predicting ED and cardiovascular
risk. However, more studies are required focusing on direct correlation of levels of prolactin,
LH, estrone, and visfatin with ED in PCOS.
Key words: Adipocyte-secreted hormones, endothelial dysfunction, estrogen, follicular
stimulating hormone, hyperandrogenism, insulin resistance, luteinizing hormone, polycystic
ovary syndrome, prolactin

\section{INTRODUCTION}

Among the endocrine disorders in reproductive age women, polycystic ovary syndrome (PCOS) is the most common disorder and can be seen in 1 in every 5 women depending on the criteria used for diagnosis. ${ }^{[1-3]}$ The commonly used criteria to diagnose PCOS are National Institutes of Health (NIH PCOS) criteria and ESHRE/ASRM or Rotterdam criteria (non-NIH PCOS).

Address for correspondence: Dr. Rajani Dube,

Department of Obstetrics and Gynaecology, Ras al-Khaimah

Medical and Health Sciences University, Al Qusaidat,

Ras al-Khaimah, United Arab Emirates.

E-mail: rajani.dube@rakmhsu.ac.ae
While NIH PCOS criteria involve two features, i.e., clinical or biochemical hyperandrogenemia (HA) (Ferriman-Gallwey score $>8$, total testosterone $>2.7 \mathrm{nmol} / \mathrm{L}$, or free androgen index $[\mathrm{FAI}]>4.5$ ) and menstrual abnormality (cycle length outside 21-35 days or $<8$ cycles/year) together with exclusion of congenital adrenal hyperplasia, androgen-secreting

This is an open access article distributed under the terms of the Creative Commons Attribution-NonCommercial-ShareAlike 3.0 License, which allows others to remix, tweak, and build upon the work non-commercially, as long as the author is credited and the new creations are licensed under the identical terms.

For reprints contact: reprints@medknow.com

Cite this article as: Dube R. Does endothelial dysfunction correlate with endocrinal abnormalities in patients with polycystic ovary syndrome?. Avicenna J Med 2016;6:91-102. 
tumors (of ovary and adrenal glands), Cushing's syndrome, hyperprolactinemia, and thyroid dysfunction. ${ }^{[4]}$ Non-NIH PCOS is diagnosed by ESHRE/ASRM or Rotterdam criteria, ${ }^{[5]}$ which takes into account any 2 of the 3 criteria, i.e., HA (clinical or biochemical), menstrual abnormality, and ultrasound evidence of polycystic ovaries (PCOs), with exclusion of other causes. ${ }^{[6]}$

There are four different phenotypes of PCOS. Clinical presentations in different phenotypes can be combinations of anovulation (ANOV), (biochemical or clinical) HA, and PCOs. ${ }^{[7]}$ It has been found that adverse metabolic profile is associated with PCOS which is more profound in patients with phenotypes 1 and 2 as compared to patients with phenotypes 3 and $4 .{ }^{[8]}$ In addition, patients with PCOS are at increased risk of development of cardiovascular disease due to increase in the prevalence of hypertension and dyslipidemia. ${ }^{[1,9]}$

Equilibrium of endothelium (lining of the vascular system) is maintained by balancing of many agonistic and antagonistic factors. A healthy endothelium, by various mechanisms (e.g., release of prostacyclin, nitric oxide [NO], and developmental endothelial locus-1), exerts its antithrombotic, anti-inflammatory, and antiproliferative action. By releasing substances such as NO and endothelin, it plays an important role in the maintenance of vascular tone. Endothelial dysfunction (ED) is a systemic process in which the endothelium loses the ability/capacity to maintain vascular equilibrium. ${ }^{[10]}$

ED is an early feature of atherosclerosis and an established predictor of cardiovascular disease risk. Different studies and meta-analyses have shown that PCOS patients have ED, endothelial inflammation, endothelial cell proliferation, and associated coagulation disorders. ${ }^{[1]]}$

PCOS is also associated with disproportionate gonadotropin secretion along with abnormalities in androgens, insulin, prolactin, and adipocyte-secreted hormones. However, it is unclear whether ED in PCOS is due to cardiovascular risk factors, inflammatory markers, or endocrinal changes, as each one of these can contribute independently to the endothelial abnormality. As severe ED is seen in PCOS which is only partially explained by known risk factors (such as obesity, increase in vascular cell adhesion molecule-1 (VCAM-1), and insulin resistance [IR] $)^{[12]}$ quest for other factors to fill this gap is on.

Various hormones have been implicated as a cause for ED in PCOS, but more and more studies now show conflicting evidence to the traditional assumptions that $\mathrm{ED}$ is related to HA and IR. ${ }^{[6]}$
In this systematic review, we aim to find out whether any of the known endocrinal abnormalities seen in PCOS explains the ED and whether there is a need for future studies correlating the levels of these hormones with ED.

\section{METHODOLOGY}

\section{Search strategy}

The databases including MEDLINE, PubMed, Up-To-Date, and ScienceDirect were searched for trials and observational studies from January 1987 to September 2015. Medical subject handling terms and free text term keywords such as endocrine abnormalities in PCOS, ED in PCOS, and assessment of ED were used. Combinations of ED with IR, HA, increased free testosterone, FAI, gonadotrophin levels, luteinizing hormone (LH), follicular stimulating hormone (FSH), prolactin, estrogen, and adipocyte-secreted hormones were used for systematic search. Free articles and abstracts were obtained, and authors of the original studies were contacted for additional data when necessary.

\section{ENDOCRINAL ABNORMALITIES IN POLYCYSTIC OVARY SYNDROME}

PCOS is associated with a range of endocrinal abnormalities [Table 1]. Conditions of androgen excess such as (androgen producing) tumors in ovary and adrenal gland, thyroid dysfunction, late onset congenital adrenal hyperplasia, hyperprolactinemia, acromegaly, and Cushing's syndrome need to be excluded before the diagnosis of PCOS is made. $^{[13-15]}$

Testosterone is secreted by the adrenal glands and ovaries, but in females, the predominant site of production is adipose tissue (from the conversion of androstenedione). In ovary, androgen production is controlled by $\mathrm{LH}$, which stimulates theca lutein cells to secrete androstenedione and testosterone. In conditions where there is a sustained increase in $\mathrm{LH}$, androstenedione increases. Within adipocytes, majority of androstenedione is converted to testosterone, but a small amount is also converted to estrone (a week estrogen). Peripheral conversion of androstenedione to testosterone is directly dependent on androstenedione levels in the body. In obesity, excess peripheral fat results in increased production of testosterone and estrone due to rise in peripheral conversion. This estrone in turn exerts positive feedback action ${ }^{[16]}$ on pituitary to further increase $\mathrm{LH}$ secretion and thus further worsening the situation.

A small fraction of patients with PCOS has elevated prolactin levels (typically in $25-40 \mathrm{ng} / \mathrm{ml}$ range). Hyperprolactinemia 


\begin{tabular}{lll}
\hline Table I: Endocrinal abnormalities seen in polycystic ovary syndrome & \\
\hline Hormone & Changes & Comment \\
\hline Androgen & $\begin{array}{l}\text { Free testosterone - elevated } \\
\text { DHEA-S - normal or slightly increased } \\
\text { SHBG - usually low }\end{array}$ & $\begin{array}{l}\text { Patients with androgen-secreting ovarian tumors - testostero } \\
\text { ne level }>I 50 \mathrm{ng} / \mathrm{dL} \\
\text { As DHEA-S is mainly derived from the adrenal gland, level }\end{array}$ \\
& Androstenedione - elevated & $>800 \mathrm{mcg} / \mathrm{dL}$ suggests adrenal tumor \\
& Within the reference range or low & Androstenedione is equally derived from ovaries and adrenals \\
FSH & Levels elevated for Tanner stage, sex, and age & The LH-to-FSH ratio is usually $>3$ \\
LH & IGFBP-I levels decreased & $70 \%$ of PCOS patients may have IR \\
Insulin & Serum insulin increased & \\
& IGF-I levels increased & \\
Prolactin & Elevated in $25 \%$ of patients & \\
Estrogen and progesterone & Estrone in greater concentration than estradiol & Levels are typically $>25 \mathrm{ng} / \mathrm{ml}$ but $<40 \mathrm{ng} / \mathrm{ml}$ \\
& Progesterone is very low & Progesterone is low due to anovulation
\end{tabular}

LH: Luteinizing hormone, FSH: Follicular stimulating Hormone, IGFBP-I: Insulin-like growth factor binding protein-I, DHEA-S: Dehydroepiandrosterone sulfate, SHBG: Sex hormone binding globulin, PCOS: Polycystic ovary syndrome, IR: Insulin resistance

as a cause of amenorrhea should be excluded before the final diagnosis of PCOS is made. ${ }^{[16]}$

There is ample evidence (in published literature) of IR being a component of hormonal abnormalities in PCOS. ${ }^{[17-26]}$ The prevalence of abnormal serum insulin levels and IR in PCOS vary between different studies, and it could be as high as $70 \%$. In addition, $20 \%$ of women could be diabetic at diagnosis of PCOS. ${ }^{[19-22]}$ As many as $70 \%$ of women with PCOS exhibit IR independent of obesity and it has been suggested that PCOS represents a female subtype of metabolic syndrome. ${ }^{[23-25]}$ IR can be particularly high in adolescents with PCOS. ${ }^{[26]}$

In a recent study, it was concluded that adolescent girls with PCOS who are at high risk of development of metabolic syndrome can be identified by IR and inflammatory markers. ${ }^{[17]}$ An earlier study has also shown that serum-free insulin-like growth factor-I (fIGF-I) levels are elevated ( $5.9 \pm 0.3$ vs. $2.7 \pm 0.3 \mathrm{ng} / \mathrm{ml} ; P<0.001)$ and IGF binding protein-1 (IGFBP-1) levels are significantly decreased $(1.0 \pm 0.2$ vs. $7.3 \pm 1.1 \mathrm{ng} / \mathrm{ml} ; P<0.001)$ in PCOS patients. IGFBP-1 levels are inversely correlated with serum insulin levels and fIGF-I levels ( $r=-0.50 ; P<10(-8)]$, $[r=-0.31 ; P=0.046]$, respectively) in patients with PCOS. ${ }^{[18]}$

In contrast, in another study involving different subsets of PCOS in 140 women, there were no differences in markers of IR such as plasma glucose and insulin levels, the glucose/insulin ratio, the area under the oral glucose tolerance test (OGTT) curve, homeostasis model assessment of IR (HOMA-IR), and quantitative insulin sensitivity check in indices between women with PCOS and controls. ${ }^{[7]}$ It is to be noted in this context that, in general, normal glucose levels on OGTT do not reflect IR and about $25 \%$ women with normal glucose levels can develop abnormalities within next 3 years. ${ }^{[27]}$
Serum-free testosterone concentrations increase in chronic hyperinsulinemia due to increase in ovarian testosterone production and decrease in the sex hormone-binding globulin (SHBG) ${ }^{[28]}$ IR is key to the development of PCOS which can be suggested by the fact that decrease in insulin levels leads to decreased androgens ${ }^{[29-31]}$ but decreased androgen levels does not improve IR. ${ }^{[32]}$

Dysregulation of adipocyte-secreted hormones (adiponectin and visfatin) is common in PCOS patients, particularly with obesity and IR. These hormones are linked to cardiovascular disorders. ${ }^{[33]}$

\section{METHODS FOR ASSESSING ENDOTHELIAL DYSFUNCTION}

ED can be assessed by measuring specific markers of coagulation (plasminogen activator inhibitor-1 [PAI-1]), inflammation (soluble intracellular cell adhesion molecule-1 [sICAM-1] and soluble VCAM-1 [sVCAM-1]), endothelium-derived circulating markers such as asymmetric dimethylarginine (ADMA), or by assessing vascular tone. ADMA is an endogenous competitive inhibitor of NO synthase and PAI-1 acts by inhibiting plasminogen activation. ${ }^{[34-40]}$

The earliest assessment of ED dates back to assessment in atherosclerotic coronary arteries by Ludmer et al. using acetylcholine infusion (into coronary artery) and quantitative angiography almost 30 years back in $1986 .{ }^{[34]}$ As the original method was invasive, less invasive, and noninvasive methods were developed later which used vessels in forearm instead of coronary arteries. ${ }^{[35-37]}$ These tests are based on the principle that healthy arteries dilate when stimulated by pharmacological agents, by release of NO and/or other endothelium-derived vasoactive substances or in response to reactive hyperemia (flow-mediated dilatation [FMD]). This 
property is decreased or even lost in disease states. ${ }^{[38]}$ These responses can be endothelium-dependent or independent. While endothelium-dependent responses reflect the state of endothelium, endothelial independent functions specifically reflect structural changes in vessels and smooth muscle cells.

Function of coronary microvasculature is assessed by changes in coronary (or myocardial) blood flow and coronary flow reserve. ${ }^{[41,42]}$ Endothelial function in coronary vessels is measured by invasive methods such as quantitative coronary angiography or intravascular ultrasound to assess changes in response to vasodilator substances (like acetylcholine) or noninvasive functional tests such as positron emission tomography, myocardial perfusion imaging, blood oxygen level-dependent magnetic resonance imaging, and echocardiography. Noninvasive tests are especially useful in individuals in whom coronary angiogram is not indicated. ${ }^{[43-49]}$

Endothelial function in peripheral vessels can be measured by semi-invasive method (venous plethysmography in forearm vessels), noninvasive method (FMD), or other methods such as finger plethysmography, measurement of blood flow changes in the skin microcirculation using laser Doppler flow (LDF) coupled with acetylcholine iontophoresis, and enclosed zone flow-mediated vasodilation (ezFMD). ${ }^{[36,50-53]}$ FMD of brachial artery is mainly NO-dependent with contributions from other pathways and is widely used in the assessment of endothelial function. However, FMD assessment needs accurate training, application, and standardization. ${ }^{[37,54-62]}$ Endothelial function in pulmonary vessels can be effectively assessed by diffusing capacity of carbon monoxide. As the values differ significantly at different days of the menstrual cycle, in patients with PCOS if such tests are performed, result is likely to be altered due to ANOV and amenorrhea. ${ }^{[63]}$

ED is now an established marker of cardiovascular risk and dysfunction. It is seen in infections, various diseases, and disorders in aged and even young children. ${ }^{[36,64-68]}$

\section{ENDOTHELIAL DYSFUNCTION IN POLYCYSTIC OVARY SYNDROME}

Various studies have reported vascular abnormalities and ED being commonly associated with PCOS. ${ }^{[40,69-75]}$ This fact is also documented in another study which showed significantly lower FMD (reduced by approximately $50 \%$; $P<0.0005$ ) and lower nitrate-mediated dilation (reduced by approximately $25 \% ; P<0.0005$ ) in women with PCOS compared to the control group. ${ }^{[71]}$ Different markers of ED such as ADMA, PAI-1, sVCAM-1, and sICAM-1 concentrations were also found to be elevated in women with PCOS compared with non-PCOS controls in a number of other studies. ${ }^{[6,74-83]}$ In one such study involving 107 subjects elevated ADMA positively correlated with increased androgens (testosterone $[P=0.002]$, FAI $[P<0.001])$, triacylglycerols $(P<0.001)$, and insulin sensitivity parameters (fasting insulin $[P=0.002]$ and HOMA-IR $[P<0.001) .{ }^{[80]}$ In another study involving 81 women, elevated ADMA in women with PCOS was found to be independent of age and adiposity. ${ }^{[6]}$ Evidence of ED can also be found by another study which showed platelet hyperaggregability and significantly impaired responses to sodium nitroprusside inhibition of platelet aggregation in patients with PCOS as compared to controls..$^{[79]}$

In contrast, endothelial function assessed by standard venous occlusion plethysmography technique to measure reactive hyperemic forearm blood flow in 11 PCOS women and 12 weight-matched controls showed no difference (PCOS: mean - 158.7, standard deviation [SD] - 135.5\%; controls: mean - 200.1, SD - 114.2\%) in another study. ${ }^{[84]}$

Furthermore, in yet another study using cardiovascular magnetic resonanceto assess endothelial function, it was found that abnormality is seen only in endothelium-dependent (FMD) and not in endothelial independent (glyceryl trinitrate) responses in PCOS $(n=14)$ patients. FMD was significantly reduced in PCOS group ( $-1 \%$ vs. $5 \%$ and $2 \%$ vs. $12 \%, P<0.01)$. ${ }^{[12]}$

Among the two meta-analyses which studied different markers of ED in women with PCOS, one included 21 studies comparing FMD in women with PCOS versus control group. This showed significantly low FMD 3.4\% (95\% confidence interval $[\mathrm{CI}]=1.9,4.9)$ even after subanalysis $4.1 \%(95 \% \mathrm{CI}=2.7,5.5)$ in PCOS group and concluded that endothelial function is compromised in women with PCOS despite being young $(P=0.38)$ and having body mass index (BMI) $(P=0.17)$ within normal range. However, there was substantial heterogeneity between studies due to differences in matching and measurements. ${ }^{[3]}$ The other meta-analysis involving 7174 cardiovascular disease markers in 2835 women with PCOS and 5076 markers in 1930 controls to study 11 different outcomes concluded that women with PCOS have significantly elevated ADMA along with other markers such as C-reactive protein (CRP), PAI-1 antigen, compared to controls though they also recorded a significant heterogeneity between studies. ${ }^{[85]}$

Furthermore, when interrelationship between different methods of assessing endothelial function and intima-media thickness (IMT) was investigated in 28 obese patients 
with PCOS, FMD of the brachial artery was found not to correlate with low-flow-mediated constriction, peripheral arterial tonometry (PAT), augmentation index (AI), and pulse wave velocity (PWV), and there was no significant interrelationship between IMT and FMD or NMD. The AI was related only to IMT $(r=0.45, P=0.30)$. This proves that as different methods investigate different mechanisms and various sections of the circulatory system; in PCOS, the relationship between available methods for evaluation of endothelial function/dysfunction is weak. ${ }^{[86]}$

\section{CORRELATION BETWEEN ENDOTHELIAL DYSFUNCTION AND ENDOCRINAL ABNORMALITIES IN POLYCYSTIC OVARY SYNDROME}

\section{Endothelial dysfunction and androgens}

The diagnosis of PCOS essentially involves demonstrable clinical or biochemical HA. Androgens are generally increased in PCOS patients, but elevated levels of testosterone and FAI are more consistently associated with PCOS than other androgens [Table 2].

In men, studies show that lower levels of total and free testosterone (but not dehydroepiandrosterone sulfate [DHEA-S] and SHBG) are independently associated with ED. ${ }^{[87-89]}$ Furthermore, some studies suggest that age-related vascular damage in men is associated with lower levels of testosterone. Supplemental testosterone is likely to improve or even reverse these changes. ${ }^{[90]}$

ED has been linked to HA in women for a long time now. ${ }^{[6,69,71,74,75,78-80]}$ In a study involving 83 women with PCOS, it was found that the levels of ADMA were elevated and positively correlated to androgen levels (free testosterone, $\mathrm{FAI}$ ) compared with controls. ${ }^{[78]}$ A prospective case-control study involving 69 patients with PCOS and 33 controls, showed free testosterone as independent predictors of ED. ${ }^{[33]}$

It was found in another study involving 13 PCOS patients that the leg blood flow increase in response to methacholine chloride infusion was $50 \%$ lower in the PCOS group than control $(P<0.01)$, and maximal increase has strongest inverse correlation with free testosterone levels $(r=-0.52$, $P<0.007) .{ }^{[69]}$

In a cross-sectional study involving 107 obese women with or without PCOS to assess different parameters of lipid, inflammatory markers, hormonal changes and ED, FAI ( $9.3 \pm 5.6$ vs. $4.6 \pm 3.8$ in controls), HOMA-IR ( $4.1 \pm 3.4$ vs. $1.9 \pm 1.4$ in controls), and lipids (total cholesterol [ $5.2 \pm 1.0 \mathrm{vs}$. $4.7 \pm 0.9 \mathrm{mmol} / \mathrm{L}$ in controls] and triacylglycerols [1.4 \pm 0.7 vs. $0.9 \pm 0.3 \mathrm{mmol} / \mathrm{L}$ in controls] $)$ were significantly higher in PCOS group $(P<0.05)$. Markers of ED were

\begin{tabular}{|c|c|c|c|c|}
\hline Author & $\begin{array}{l}\text { Hormone } \\
\text { involved }\end{array}$ & Assessment of ED & $\begin{array}{l}\text { Number of } \\
\text { subjects }\end{array}$ & Findings \\
\hline Pepene & Free testosterone & FMD & 69 & Free testosterone is independent predictor of FMD \\
\hline Paradisi et al. & Free testosterone & Maximal LBF response to $\mathrm{MCh}$ & 13 & $\begin{array}{l}\text { The inverse correlation between testosterone and } \\
\text { blood flow }(r=-0.52, P<0.007) \text { is stronger than other } \\
\text { parameters }\end{array}$ \\
\hline Kravariti et al. & $\begin{array}{l}\text { Total } \\
\text { testosterone }\end{array}$ & $\begin{array}{l}\text { FMD and nitrate-mediated } \\
\text { dilation in the brachial artery }\end{array}$ & 62 & $\begin{array}{l}\text { FMD and nitrate-mediated dilation were significantly } \\
\text { lower in PCOS than in control (reduced by } \\
\text { approximately } 50 \text { and } 25 \% \text {, respectively; both } P<0.0005 \text { ) } \\
\text { Total testosterone is independent predictor of FMD, } \\
\text { accounts to } 10 \% \text { of variance }\end{array}$ \\
\hline Diamanti-Kandarakis et al. & Testosterone & Doppler sonography evaluation & 34 & $\begin{array}{l}\text { Increased carotid intima-media thickness in PCOS } \\
\text { women was directly related to androgen excess }\end{array}$ \\
\hline Heutling et al. & $\begin{array}{l}\text { Free } \\
\text { testosterone, FAI }\end{array}$ & ADMA levels & 83 & Positive correlation between ADMA and androgen levels \\
\hline Ozgurtas et al. & Testosterone & ADMA & 44 & ADMA significantly higher in PCOS patients \\
\hline Moran et al. & $\mathrm{FAI}$ & $\begin{array}{l}\text { ADMA } \\
\text { PAI-I } \\
\text { FMD }\end{array}$ & 80 & $\begin{array}{l}\text { Elevated ADMA }(I .0 \pm 0.4 \text { compared } 0.3 \pm 0 . I \text { mumol } / L \text {, } \\
P<0.00 \mathrm{I}) \text { and } \mathrm{PAI}-\mathrm{I}(5.6 \pm \mathrm{I} .8 \text { compared with } \\
4.6 \pm \mathrm{I} . \mathrm{I} \text { units } / \mathrm{ml}, P=0.006) \text {, trend toward worsened } \\
\text { FMD }(I I .8 \pm 5.0 \text { compared with } \mathrm{I} 3.5 \pm 4.0 \%, P=0.075) \text {. ED } \\
\text { is related to hyperandrogenism }\end{array}$ \\
\hline Brinkworth et al. & $\begin{array}{l}\text { Testosterone and } \\
\text { FAl }\end{array}$ & FMD & 12 & $\begin{array}{l}\text { FMD was similar in both groups (PCOS } 6.1 \pm 1.2 \% \text { vs. } \\
\text { control } 5.6 \pm 1.0 \%, P=0.77 \text { ). In PCOS with normal insulin } \\
\text { levels, ED is similar with or without increased androgens }\end{array}$ \\
\hline Sprung et al. & Testosterone & FMD & 19 & $\begin{array}{l}\text { FMD was impaired in PCOS by } 4.2 \%(95 \% \mathrm{Cl}, 2.4-6.1 \text {; } \\
P<0.00 \mathrm{I}) \\
\text { ED in PCOS is not explained by body fat distribution or } \\
\text { volume }\end{array}$ \\
\hline
\end{tabular}


also elevated (ADMA $[1.0 \pm 0.4$ vs. $0.3 \pm 0.1 \mathrm{mumol} / \mathrm{L}$, $P<0.001]$, PAI-1 [5.6 \pm 1.8 vs. $4.6 \pm 1.1$ units $/ \mathrm{ml}, P=0.006]$ ), and there was worsening of FMD (11.8 \pm 5.0 vs. $13.5 \pm 4.0 \%$, $P=0.075)$ in PCOS group. ${ }^{[80]}$

However, in another study involving 12 overweight/obese women with PCOS and 10 overweight/obese controls without PCOS, it was found that despite having high testosterone and FAI $(P<0.001$ and $P=0.006$, respectively), the FMD of PCOS was not different from controls (PCOS $6.1 \pm 1.2 \%$ vs. control $5.6 \pm 1.0 \%, P=0.77$ ) when both groups were normoinsulinemic. ${ }^{[91]}$

It was also apparent in another study that $\mathrm{ED}$ in patients with HA and PCOS is not explained by volume or distribution of body fat. ${ }^{[92]}$

Again, when the effect of 6 months treatment of spironolactone (androgen antagonist) was studied in thirty nonobese patients with PCOS in yet another study, it was found that the FMD was significantly increased $(P=0.034)$ after treatment, suggesting the role of androgens in ED. ${ }^{[93]}$

It should be noted that there is considerable gender variation in endothelial function owing to secondary effects of sex hormones (like changes in lipid profile), ${ }^{[94,95]}$ and the possibility of testosterone exerting estrogenic effect after being converted to estrogen by aromatase cannot be ruled out, especially in women with PCOS. ${ }^{[96]}$

\section{Endothelial dysfunction and gonadotrophins} (follicular stimulating hormone, luteinizing hormone) As mentioned earlier, levels of LH are strikingly increased in PCOS which is augmented by estrone, and levels of FSH are either normal or slightly decreased resulting in increased LH/FSH ratio characteristic of PCOS. ${ }^{[75]}$

Studies of cardiovascular risk and ED in PCOS patients have shown that LH levels are consistently high in them. Actual correlations of LH levels with endothelial functions have been done in experimental studies and in other disorders such as ulcerative colitis and chronic kidney disease (CKD), ${ }^{[97]}$ but specific studies in humans addressing that issue in PCOS patients has not been explored much in literature.

\section{Endothelial dysfunction and insulin}

IR has been linked to ED in PCOS for over 25 years now [Table 3]. $\cdot^{[6,69,71,74,75,78,80,83,98]}$ It was also seen that PCOS patients with IR have CRP abnormalities, lipid abnormalities, and other cardiovascular risk despite having normal glucose levels. ${ }^{[99]}$ However, the results are not consistent.
In one of the prospective studies involving fifty women with PCOS and fifty matched controls, findings suggested that young women with PCOS have altered endothelial function which correlated with IR and lower adiponectin. ${ }^{[71]}$ This fact can be substantiated by yet another study in which the FMD was not found to be different (PCOS $6.1 \pm 1.2 \%$ vs. control $5.6 \pm 1.0 \%, P=0.77$ ) in obese PCOS patients with normal insulin compared to controls suggesting a direct role of IR in ED. ${ }^{[91]}$ In a similar study involving eighty obese/overweight PCOS women, FMD was worse $(P=0.075)$ and levels of ADMA and PAI-1 were significantly elevated $(P<0.001$ and $P=0.006$, respectively). HOMA-IR was elevated $(4.1 \pm 3.4$ vs. $1.9 \pm 1.4)$ and ED (ADMA $[P=0.002]$, PAI- $1 P<0.001])$ was significantly raised as the levels (tertiles) of HOMA-IR increased. However, there was no change in von Willebrand factor as compared to non-PCOS controls with similar weight and BMI. ${ }^{[80]}$

Evidence of ED being associated with IR can also be obtained from a study in which levels of PAI-1 was elevated in PCOS patients which directly correlated with insulin levels. Insulin infusion in these patients resulted in increased PAI-1 expression. However, this effect was sustained but delayed in those with IR $(P<0.01) .{ }^{[76]}$ Indirect evidence of IR being associated with ED can be obtained by studies where patients of PCOS on metformin (insulin sensitizer) showed improvement in inflammatory markers and endothelial function (FMD and ADMA). ${ }^{[83,100]}$ Furthermore, a recently published study found that 12 weeks treatment of metformin significantly decreased levels of ICAM-1, E-selectin, interleukin-6, tumor necrosis factor, glucose, and hormones such as FSH and androstenedione, whereas it increased levels of DHEA-S in patients with PCOS (40 cases vs. 44 controls). Metformin also benefited these women by decreasing polymorphonuclear rolling flux and adhesion. ${ }^{[101]}$ Furthermore, in a review published in 2014, the levels of pro-inflammatory advanced glycation end-products (AGEs) and their receptors (RAGE) were found to be high in obesity. It was concluded that obesity can compromise ovarian function as seen in women with PCOS but mechanism behind this action is unclear. ${ }^{[102]}$ In another independent study, the levels of AGE were higher in women with PCOS $(7.96 \pm 1.87 \mathrm{U} / \mathrm{ml}, P<0.001)$ compared to controls $(5.86 \pm 0.89 \mathrm{U} / \mathrm{ml})$. The AGE levels were significantly higher in PCOS compared to isolated HA $(5.61 \pm 0.61 \mathrm{U} / \mathrm{ml})$, ANOV $(5.53 \pm 1.06 \mathrm{U} / \mathrm{ml})$, or ultrasound detected PCO morphology (without PCOS) $(5.26 \pm 0.25 \mathrm{U} / \mathrm{ml}) \cdot{ }^{[103]}$ AGEs play an important role in linking metabolic and reproductive disturbances in PCOS, and there are evidences to suggest that interventions to block RAGE might be beneficial in IR. ${ }^{[104]}$ It was also reported that RAGE expression was 


\section{Table 3: Endothelial dysfunction and insulin}

\begin{tabular}{|c|c|c|c|c|}
\hline Author & Parameter & Assessment of ED & $\begin{array}{l}\text { Number } \\
\text { of subjects }\end{array}$ & Findings \\
\hline Paradisi et al. & Serum insulin level & $\begin{array}{l}\text { LBF in response to } \\
\text { methacholine infusion }\end{array}$ & 12 & $\begin{array}{l}\text { Hyperinsulinemia caused LBF to rise above } \\
\text { baseline by approximately } 30 \% \text { in PCOS and by } \\
\text { nearly } 60 \% \text { in OBW subjects }(P<0.05)\end{array}$ \\
\hline \multirow[t]{2}{*}{ Kravariti et al. } & IR & $\begin{array}{l}\text { FMD and } \\
\text { nitrate-mediated dilation } \\
\text { in the brachial artery }\end{array}$ & 62 & $\begin{array}{l}\text { FMD and nitrate-mediated dilation were } \\
\text { significantly lower in PCOS than in } \\
\text { control (reduced by approximately } 50 \text { and } 25 \% \text {, } \\
\text { respectively; both } P<0.0005 \text { ) }\end{array}$ \\
\hline & & & & $\begin{array}{l}\mathrm{IR} \text { is an independent predictor of FMD, } \\
\text { accounting for } 21 \% \text { variance }(P<0.005) \text {. Trend } \\
\text { of deterioration in FMD increase with BMI but } \\
\text { insignificantly }\end{array}$ \\
\hline $\begin{array}{l}\text { Diamanti-Kandarakis } \\
\text { et al. }\end{array}$ & $\begin{array}{l}\text { Effect of metformin treatment } \\
\text { (indirect evidence) }\end{array}$ & sICAM-I, sE-selectin & 62 & $\begin{array}{l}\text { Metformin decreases levels of plasma } \\
\text { inflammatory indices }\end{array}$ \\
\hline Carmassi et al. & Serum insulin level & TPAI-I & 64 & $\begin{array}{l}\text { Increased TPAI-I correlated directly with } \\
\text { insulin levels. Vasodilatory response to insulin } \\
\text { was blunted }(P<0.0 \mathrm{I}) \text { and TPAI-I expression } \\
\text { abolished in insulin-resistant patients }(P<0.0 \mathrm{I})\end{array}$ \\
\hline Heutling et al. & $\begin{array}{l}\text { Parameters of insulin sensitivity AUC } \\
\text { insulin, homeostatic assessment of IR, } \\
\text { fasting insulin, glycosylated hemoglobin }\end{array}$ & ADMA, IMT & 83 & $\begin{array}{l}\text { ADMA levels positively correlated with } \\
\text { parameters of insulin sensitivity }\end{array}$ \\
\hline Moran et al. & HOMA-IR & FMD, ADMA, PAI-I, vWF & 80 & $\begin{array}{l}\text { ADMA }(P=0.002), P A I-I(P<0.00 I) \text { was } \\
\text { significantly raised as the levels (tertiles) of } \\
\text { HOMA-IR increased. Worse FMD in IR, no } \\
\text { change in vWF }\end{array}$ \\
\hline Brinkworth et al. & Serum insulin level & $\begin{array}{l}\text { FMD of the brachial } \\
\text { artery using hr-USG }\end{array}$ & 12 & $\begin{array}{l}\text { FMD was similar (PCOS } 6.1 \pm 1.2 \% \text { versus } \\
\text { control } 5.6 \pm 1.0 \%, P=0.77) \text { in absence of } I R\end{array}$ \\
\hline Tarkun et al. & & $\begin{array}{l}\text { Brachial artery } \\
\text { responses to } \\
\text { endothelium-dependent } \\
\text { and independent stimuli, } \\
\text { hsCRP concentrations }\end{array}$ & 37 & $\begin{array}{l}\text { Endothelium-dependent vasodilation was } \\
\text { correlated with hsCRP concentrations and IR } \\
\text { hsCRP concentrations were correlated with } \\
\text { insulin sensitivity indices (HOMA-IR) and } \\
\text { quantitative insulin sensitivity check index }\end{array}$ \\
\hline Mather et al. & Glucose/insulin ratio & $\begin{array}{l}\text { Endothelium-dependent } \\
\text { and } \\
\text { endothelium-independent } \\
\text { vascular responses }\end{array}$ & 18 & $\begin{array}{l}\text { Marked difference in glucose/insulin } \\
\text { ratio }(6 . I \pm I . I \mathrm{mmol} / \mathrm{pmol} \text { vs. } 9.9 \pm 0.6 \text { (controls)) } \\
\text { Both endothelium-dependent }(8.7 \pm 3.1 \%) \text { and } \\
\text { independent }(23.2 \pm 3.4 \%) \text { vascular responses } \\
\text { were normal } \\
\text { No correlation between degree of IR and the } \\
\text { brachial response }\end{array}$ \\
\hline Victor et al. & Effect of metformin treatment & $\begin{array}{l}\text { ICAM-I, E-selectin, IL-6, } \\
\text { TNF } \alpha\end{array}$ & 40 & $\begin{array}{l}\text { In addition, decrease in inflammatory } \\
\text { parameters, the levels of glucose and } \\
\text { hormones (FSH and androstenedione) } \\
\text { decreased while levels of DHEA-S increased } \\
\text { after } 12 \text { weeks treatment with metformin }\end{array}$ \\
\hline Yavuz Tașlipinar et al. & HOMA-IR rates & ADMA, NO levels & 50 & $\begin{array}{l}\text { ADMA levels and HOMA-IR rates are } \\
\text { significantly increased }(P=0.00 \mathrm{I} \text { in both }) \text { and } \\
\text { NO levels are significantly decreased }(P=0.008) \\
\text { in women with PCOS }\end{array}$ \\
\hline
\end{tabular}

BMI: Body mass index, FSH: Follicular stimulating hormone, FMD: Flow-mediated dilatation, HOMA-IR: Homoeostasis model assessment-insulin resistance, vWF: von Willebrand factor, LBF: Leg blood flow, sICAM-I:Soluble intracellular cell adhesion molecule-I, sE-selectin: Soluble endothelial leukocyte adhesion molecule-I, IMT:Intima-media thickness,AUC: Area under the curve, PAT: Peripheral arterial tonometry, PWVc: Central pulse wave velocity, hsCRP: High-sensitivity C-reactive protein, hr-USG: High resolution ultrasonography, NO: Nitric oxide, TPAI-I: Tissue plasminogen activator inhibitor-I, NO: Nitric oxide, ED: Endothelial dysfunction, IL: Interleukin, TNF- $\alpha$ : Tumor necrosis factor-alpha, DHEA-s: Dehydroepiandrosterone sulfate, PAI-I:Plasminogen activator inhibitor-I, OBW: OBese without PCOS

stronger in granulosa cells than theca cells in ovaries of PCOS patients compared to controls. ${ }^{[105]}$ These studies further support the possible role of IR.

However, the association between IR and ED is contradicted by other studies. ${ }^{[6,106-108]}$ In a cross-sectional study involving 54 overweight NIH and non-NIH PCOS patients assessing vascular health and endothelial function by ADMA,
PAI-1, PAT, and arterial stiffness (central PWV [PWVc]), it was found that ADMA was high but PAI-1 $(P=0.20)$, PAT $(P=0.95)$, and PWVc $(P=0.67)$ were similar in PCOS as compared to controls even after adjustments, in spite of having IR. ${ }^{[6]}$ In another study involving 19 overweight/obese PCOS patients using EndoPAT (reactive hyperemia index $[\mathrm{RHI}]$ ) device for assessing endothelial function, it was seen that these women have sympathetic activation and 
ED (RHI: $1 \cdot 77 \pm 0 \cdot 14$ vs. $2 \cdot 18 \pm 0 \cdot 14, P<0 \cdot 05)$. These changes are not dependent on metabolic disturbances or obesity. ${ }^{[106]}$ It was also found that there can be normal endothelial function despite IR in healthy women with PCOS by another study. ${ }^{[107]}$ Furthermore, in yet another study involving 25 women with PCOS and 25 healthy controls, significantly increased plasma ADMA levels $(P=0.001)$ and HOMA-IR rates $(P=0.001)$ were found in PCOS patients than in the controls. Serum levels of NO (vasodilator) were also significantly lower in patients than in the controls $(P=0.008)$. Although results indicated that there is a significant IR in PCOS patients independent of age, BMI, and blood lipid profile, there was no correlation between HOMA-IR and markers of ED (altered ADMA and NO levels). ${ }^{[108]}$

These studies certainly indicate the possibility of involvement of additional mechanisms (of cardiovascular risks) in PCOS patients other than IR.

\section{Endothelial dysfunction and prolactin}

As mentioned earlier prolactin levels are increased in a small percentage of patients with PCOS.

Prolactin levels were studied and found to be directly associated with $\mathrm{ED} /$ stiffness, increased risk of cardiovascular events, and mortality in patients of CKD. ${ }^{[97]}$ Although hyperprolactinemia itself does not have clear effects on the cardiovascular system, there is a possible association between long-term treatment with dopamine agonists and cardiac valve abnormalities. ${ }^{[109]}$

These findings suggest that there can be a possible correlation between prolactin levels and ED in PCOS which needs to be explored further by direct correlation studies.

\section{Endothelial dysfunction, estrogen, and progesterone}

The role of estrogen in women for maintenance of vascular health is well known and can be substantiated by the fact that around the time of menopause, there is a steep decline in FMD. Corresponding to endocrinal changes in menstrual cycle, it was found that maximal endothelium-dependent vasodilatation occurs in follicular and luteal phases of the menstrual cycle (high estradiol), but during menstruation (low estradiol), endothelial function is similar to that of healthy males. ${ }^{[96]}$

Furthermore, it was found that premenopausal women and women receiving estrogen replacement therapy (ERT) have less cardiovascular events than postmenopausal women without ERT. ${ }^{[110,111]}$ It was also reported by another study that ERT improves endothelial function. ${ }^{[112]}$ Similarly, a positive association between $\mathrm{NO}$ (and endothelial function) and the free estradiol levels was found in postmenopausal women, not on ERT in another study. ${ }^{[113]}$ It was also found in a study involving 106 women with PCOS that ADMA levels decrease when women receive estrogen as a part of treatment and (independent of IR) ED in PCOS patients can be reversed by treatment with estrogens and antiandrogens. ${ }^{[77]}$ A recent study $(n=15)$ showed that addition of estradiol to women receiving progesterone for contraception improves endothelium-dependent FMD in them. ${ }^{[14]}$

However, as opposed to normal women, the estrogen that increases in PCOS is estrone (vs. estradiol in premenopausal women). Estrone is considered a weaker form of estrogen which needs to be converted to estradiol for action. The effect of increased estrone on endothelial function has not been studied much in PCOS patients.

\section{Endothelial dysfunction and adipocytokines}

Adipocytokines such as leptin, adiponectin, pro-inflammatory cytokines, resistin, retinol binding protein 4 , and visfatin have long been thought to be responsible for $\mathrm{ED}$, especially in PCOS women in the presence of obesity. ${ }^{[115]}$ A recent study showed an increase in adipocyte-secreted hormone visfatin in PCOS patient which directly correlated with free testosterone levels $(P=0.024)$ and brachial artery FMD $(P=0.008 ; P<0.01$ in multivariate analyses). Visfatin was found to be independent predictor of FMD not confounded by age, BMI, total body fat mass, testosterone, SHBG, or HOMA-IR. ${ }^{[33]}$ A recently published review further suggests that different activity of adipocytokines affect metabolic changes seen in women with PCOS and also indicate a possible role of these cytokines in regulation of insulin sensitivity. ${ }^{[16]}$ However, larger studies are required to further substantiate this association.

\section{CONCLUSION}

PCOS increases the risk of cardiovascular disease in women. There is ample evidence that $\mathrm{ED}$, which is a reliable indicator of cardiovascular risk in general population and is associated with many disease states, is seen in most (but not all) women with PCOS. Some of the markers of ED (ADMA) are consistently associated with PCOS, but when ED is assessed by other methods such as venous occlusion plethysmography, the association is not strong and is rather controversial. It can be concluded from the available evidences that ED in PCOS is endothelial dependent. It is also evident that ED in PCOS is independent of age and obesity which are risk factors associated with ED in general population. Furthermore, as the use of available methods for ED is unreliable in PCOS, there is a need for adopting a standard method for 
endothelial function evaluation in PCOS and use of ezFMD and LDF coupled with acetylcholine iontophoresis should be preferred over other methods for this purpose.

Although 70\% women with PCOS have some or the other parameter of IR, IR per se cannot be solely attributed to ED in PCOS due to conflicting evidences. However, there is a need for more research, especially in women with IR and PCOS concentrating on interventions to slow down the AGE-RAGE axis to study their effect on existing ED.

HA (specifically free testosterone and FAI) is consistently associated with ED. However, based on the observations, the association of HA (although more often present) with ED in women with PCOS cannot be taken as reliable.

Serum levels of estrone are increased in patients with PCOS as compared to estradiol which is believed to offer protection against ED. However, there is a paucity of studies comparing estrone levels with $\mathrm{ED}$, and more studies are needed to directly correlate them.

LH plays a very important role in the pathogenesis of PCOS. Studies correlating LH levels with ED are required in patients with PCOS. Prolactin levels are elevated only in a small percentage of women with PCOS. There is a need for more studies in PCOS patients to establish correlation between prolactin levels and ED.

Adipocytokines (by regulating insulin sensitivity and ED) have a promising role in predicting ED and cardiovascular risk. Published data regarding this correlation are however inadequate and more studies are required to corroborate the findings.

\section{Financial support and sponsorship}

Nil.

\section{Conflicts of interest}

There are no conflicts of interest.

\section{REFERENCES}

1. Norman RJ, Dewailly D, Legro RS, Hickey TE. Polycystic ovary syndrome. Lancet 2007;370:685-97.

2. March WA, Moore VM, Willson KJ, Phillips DI, Norman RJ, Davies MJ. The prevalence of polycystic ovary syndrome in a community sample assessed under contrasting diagnostic criteria. Hum Reprod 2010;25:544-51.

3. Sprung VS, Atkinson G, Cuthbertson DJ, Pugh CJ, Aziz N, Green DJ, et al. Endothelial function measured using flow-mediated dilation in polycystic ovary syndrome: A meta-analysis of the observational studies. Clin Endocrinol (Oxf) 2013;78:438-46.

4. Zawadzki J, Dunaif A. Diagnostic criteria for polycystic ovary syndrome: Towards a rational approach. Current Issues in Endocrinology and
Metabolism. Boston: Blackwell Scientific; 1992. p. 377-84.

5. Rotterdam ESHRE/ASRM-Sponsored PCOS Consensus Workshop Group. Revised 2003 consensus on diagnostic criteria and long-term health risks related to polycystic ovary syndrome. Fertil Steril 2004;81:19-25.

6. Moran LJ, Cameron JD, Strauss BJ, Teede HJ. Vascular function in the diagnostic categories of polycystic ovary syndrome. Hum Reprod 2011;26:2192-9.

7. Koiou E, Tziomalos K, Katsikis I, Dinas K, Tsourdi EA, Kandaraki EA, et al. Plasma von Willebrand factor antigen levels are elevated in the classic phenotypes of polycystic ovary syndrome. Hormones (Athens) 2012;11:77-85.

8. Diamanti-Kandarakis E, Panidis D. Unravelling the phenotypic map of polycystic ovary syndrome (PCOS): A prospective study of 634 women with PCOS. Clin Endocrinol (Oxf) 2007;67:735-42.

9. Wild RA, Carmina E, Diamanti-Kandarakis E, Dokras A, Escobar-Morreale HF, Futterweit W, et al. Assessment of cardiovascular risk and prevention of cardiovascular disease in women with the polycystic ovary syndrome: A consensus statement by the Androgen Excess and Polycystic Ovary Syndrome (AE-PCOS) Society. J Clin Endocrinol Metab 2010;95:2038-49.

10. Butt M, Dwivedi G, Blann A, Khair O, Lip GY. Endothelial dysfunction: Methods of assessment \& implications for cardiovascular diseases. Curr Pharm Des 2010;16:3442-54.

11. Toulis KA, Goulis DG, Mintziori G, Kintiraki E, Eukarpidis E, Mouratoglou SA, et al. Meta-analysis of cardiovascular disease risk markers in women with polycystic ovary syndrome. Hum Reprod Update 2011;17:741-60.

12. Sorensen MB, Franks S, Robertson C, Pennell DJ, Collins P. Severe endothelial dysfunction in young women with polycystic ovary syndrome is only partially explained by known cardiovascular risk factors. Clin Endocrinol (Oxf) 2006;65:655-9.

13. Vause TD, Cheung AP, Sierra S, Claman P, Graham J, Guillemin JA, et al. Ovulation induction in polycystic ovary syndrome. J Obstet Gynaecol Can 2010;32:495-502.

14. American College of Obstetricians and Gynecologists. Polycystic Ovary Syndrome. ACOG Practice Bulletin No. 108. Washington, DC: American College of Obstetricians and Gynecologists; 2009.

15. Royal College of Obstetricians and Gynaecologists. Long-term consequences of polycystic ovary syndrome. Green-top Guideline No. 33. London, UK: Royal College of Obstetricians and Gynaecologists; 2007.

16. Beckmann CR, Ling FW, Herbert WN, Smith RP, Casanova R, Chuang A, et al. From hirsutism and virilization. In: Beckmann CR, editor. Obstetrics and Gynecology. $7^{\text {th }}$ ed. Philadelphia, PA: Lippincott Williams \& Wilkins; 2014. p. 358.

17. Alemzadeh R, Kichler J, Calhoun M. Spectrum of metabolic dysfunction in relationship with hyperandrogenemia in obese adolescent girls with polycystic ovary syndrome. Eur J Endocrinol 2010;162:1093-9.

18. Thierry van Dessel HJ, Lee PD, Faessen G, Fauser BC, Giudice LC. Elevated serum levels of free insulin-like growth factor I in polycystic ovary syndrome. J Clin Endocrinol Metab 1999;84:3030-5.

19. Freeman R, Pollack R, Rosenbloom E. Assessing impaired glucose tolerance and insulin resistance in polycystic ovarian syndrome with a muffin test: An alternative to the glucose tolerance test. Endocr Pract 2010;16:810-7.

20. Farrell K, Antoni MH. Insulin resistance, obesity, inflammation, and depression in polycystic ovary syndrome: Biobehavioral mechanisms and interventions. Fertil Steril 2010;94:1565-74.

21. Ovalle F, Azziz R. Insulin resistance, polycystic ovary syndrome, and type 2 diabetes mellitus. Fertil Steril 2002;77:1095-105.

22. Indhavivadhana S, Wongwananuruk T, Rattanachaiyanont $\mathrm{M}$, Techatraisak K, Leerasiri P, Tanmahasamut P, et al. Prevalence of metabolic syndrome in reproductive-aged polycystic ovary syndrome Thai women. J Med Assoc Thai 2010;93:653-60. 
23. Burghen GA, Givens JR, Kitabchi AE. Correlation of hyperandrogenism with hyperinsulinism in polycystic ovarian disease. J Clin Endocrinol Metab 1980;50:113-6.

24. Goodarzi MO, Korenman SG. The importance of insulin resistance in polycystic ovary syndrome. Fertil Steril 2003;80:255-8.

25. Glueck CJ, Morrison JA, Goldenberg N, Wang P. Coronary heart disease risk factors in adult premenopausal white women with polycystic ovary syndrome compared with a healthy female population. Metabolism 2009;58:714-21.

26. Bhattacharya SM, Ghosh M. Insulin resistance and adolescent girls with polycystic ovary syndrome. J Pediatr Adolesc Gynecol 2010;23:158-61.

27. Pesant MH, Baillargeon JP. Clinically useful predictors of conversion to abnormal glucose tolerance in women with polycystic ovary syndrome. Fertil Steril 2011;95:210-5.

28. Barbieri RL, Smith S, Ryan KJ. The role of hyperinsulinemia in the pathogenesis of ovarian hyperandrogenism. Fertil Steril 1988;50:197-212.

29. Dunaif A, Graf M, Mandeli J, Laumas V, Dobrjansky A. Characterization of groups of hyperandrogenic women with acanthosis nigricans, impaired glucose tolerance, and/or hyperinsulinemia. J Clin Endocrinol Metab 1987;65:499-507.

30. Franks S. Polycystic ovary syndrome: A changing perspective. Clin Endocrinol (Oxf) 1989;31:87-120.

31. Utiger RD. Insulin and the polycystic ovary syndrome. N Engl J Med 1996;335:657-8.

32. Lanzone A, Fulghesu AM, Andreani CL, Apa R, Fortini A, Caruso A, et al. Insulin secretion in polycystic ovarian disease: Effect of ovarian suppression by GnRH agonist. Hum Reprod 1990;5:143-9.

33. Pepene CE. Evidence for visfatin as an independent predictor of endothelial dysfunction in polycystic ovary syndrome. Clin Endocrinol (Oxf) 2012;76:119-25.

34. Ludmer PL, Selwyn AP, Shook TL, Wayne RR, Mudge GH, Alexander RW, et al. Paradoxical vasoconstriction induced by acetylcholine in atherosclerotic coronary arteries. N Engl J Med 1986;315:1046-51.

35. Anderson TJ, Gerhard MD, Meredith IT, Charbonneau F, Delagrange D, Creager MA, et al. Systemic nature of endothelial dysfunction in atherosclerosis. Am J Cardiol 1995;75:71B-4B.

36. Linder L, Kiowski W, Bühler FR, Lüscher TF. Indirect evidence for release of endothelium-derived relaxing factor in human forearm circulation in vivo. Blunted response in essential hypertension. Circulation 1990;81:1762-7.

37. Celermajer DS, Sorensen KE, Gooch VM, Spiegelhalter DJ, Miller OI, Sullivan ID, et al. Non-invasive detection of endothelial dysfunction in children and adults at risk of atherosclerosis. Lancet 1992;340:1111-5.

38. Flammer AJ, Lüscher TF. Human endothelial dysfunction: EDRFs. Pflugers Arch 2010;459:1005-13.

39. Thomson RL, Brinkworth GD, Noakes M, Clifton PM, Norman RJ, Buckley JD. The effect of diet and exercise on markers of endothelial function in overweight and obese women with polycystic ovary syndrome. Hum Reprod 2012;27:2169-76.

40. Ilie IR, Pepene CE, Duncea I, Ilie R. Vascular abnormalities and low-grade chronic inflammation in women with polycystic ovary syndrome: Relationships with insulin resistance, obesity and hyperandrogenemia. Cent Eur J Med 2008;3:257-70.

41. Beltrame JF, Crea F, Camici P. Advances in coronary microvascular dysfunction. Heart Lung Circ 2009;18:19-27.

42. Camici PG, Crea F. Coronary microvascular dysfunction. N Engl J Med 2007;356:830-40.

43. Schindler TH, Schelbert HR, Quercioli A, Dilsizian V. Cardiac PET imaging for the detection and monitoring of coronary artery disease and microvascular health. JACC Cardiovasc Imaging 2010;3:623-40.

44. Doyle M, Fuisz A, Kortright E, Biederman RW, Walsh EG, Martin ET, et al. The impact of myocardial flow reserve on the detection of coronary artery disease by perfusion imaging methods: An NHLBI WISE study.
J Cardiovasc Magn Reson 2003;5:475-85.

45. Utz W, Jordan J, Niendorf T, Stoffels M, Luft FC, Dietz R, et al. Blood oxygen level-dependent MRI of tissue oxygenation: Relation to endothelium-dependent and endothelium-independent blood flow changes. Arterioscler Thromb Vasc Biol 2005;25:1408-13.

46. Leung DY, Leung M. Non-invasive/invasive imaging: Significance and assessment of coronary microvascular dysfunction. Heart 2011;97:587-95.

47. Anderson TJ, Uehata A, Gerhard MD, Meredith IT, Knab S, Delagrage D, et al. Close relation of endothelial function in the human coronary and peripheral circulation. J Am Coll Cardiol 1995;26:1235-41.

48. Bonetti PO, Pumper GM, Higano ST, Holmes DR Jr., Kuvin JT, Lerman A. Noninvasive identification of patients with early coronary atherosclerosis by assessment of digital reactive hyperemia. J Am Coll Cardiol 2004;44:2137-41.

49. Takase B, Uehata A, Akima T, Nagai T, Nishioka T, Hamabe A, et al. Endothelium-dependent flow-mediated vasodilation in coronary and brachial arteries in suspected coronary artery disease. Am J Cardiol 1998;82:1535-9, A7-8.

50. Kuvin JT, Patel AR, Sliney KA, Pandian NG, Sheffy J, Schnall RP, et al. Assessment of peripheral vascular endothelial function with finger arterial pulse wave amplitude. Am Heart J 2003;146:168-74.

51. Lavie P, Schnall RP, Sheffy J, Shlitner A. Peripheral vasoconstriction during REM sleep detected by a new plethysmographic method. Nat Med 2000;6:606.

52. Debbabi H, Bonnin P, Ducluzeau PH, Lefthériotis G, Levy BI. Noninvasive assessment of endothelial function in the skin microcirculation. Am J Hypertens 2010;23:541-6.

53. Idei N, Ukawa T, Kajikawa M, Iwamoto Y, Fujimura N, Maruhashi T, et al. A novel noninvasive and simple method for assessment of endothelial function: Enclosed zone flow-mediated vasodilation (ezFMD) using an oscillation amplitude measurement. Atherosclerosis 2013;229:324-30.

54. Joannides R, Haefeli WE, Linder L, Richard V, Bakkali EH, Thuillez C, et al. Nitric oxide is responsible for flow-dependent dilatation of human peripheral conduit arteries in vivo. Circulation 1995;91:1314-9.

55. Lieberman EH, Gerhard MD, Uehata A, Selwyn AP, Ganz P, Yeung AC, et al. Flow-induced vasodilation of the human brachial artery is impaired in patients $<40$ years of age with coronary artery disease. Am J Cardiol 1996;78:1210-4.

56. Joannides R, Richard V, Haefeli WE, Linder L, Lüscher TF, Thuillez C. Role of basal and stimulated release of nitric oxide in the regulation of radial artery caliber in humans. Hypertension 1995;26:327-31.

57. Parker BA, Tschakovsky ME, Augeri AL, Polk DM, Thompson PD, Kiernan FJ. Heterogenous vasodilator pathways underlie flow-mediated dilation in men and women. Am J Physiol Heart Circ Physiol 2011;301:H1118-26.

58. Corretti MC, Anderson TJ, Benjamin EJ, Celermajer D, Charbonneau F, Creager MA, et al. Guidelines for the ultrasound assessment of endothelial-dependent flow-mediated vasodilation of the brachial artery: A report of the International Brachial Artery Reactivity Task Force. J Am Coll Cardiol 2002;39:257-65.

59. Deanfield J, Donald A, Ferri C, Giannattasio C, Halcox J, Halligan S, et al. Endothelial function and dysfunction. Part I: Methodological issues for assessment in the different vascular beds: A statement by the Working Group on Endothelin and Endothelial Factors of the European Society of Hypertension. J Hypertens 2005;23:7-17.

60. Charakida M, Masi S, Lüscher TF, Kastelein JJ, Deanfield JE. Assessment of atherosclerosis: The role of flow-mediated dilatation. Eur Heart J 2010;31:2854-61.

61. Thijssen DH, Black MA, Pyke KE, Padilla J, Atkinson G, Harris RA, et al. Assessment of flow-mediated dilation in humans: A methodological and physiological guideline. Am J Physiol Heart Circ Physiol 2011;300:H2-12.

62. Harris RA, Nishiyama SK, Wray DW, Richardson RS. Ultrasound assessment of flow-mediated dilation. Hypertension 2010;55:1075-85. 
63. Sansores RH, Abboud RT, Kennell C, Haynes N. The effect of menstruation on the pulmonary carbon monoxide diffusing capacity. Am J Respir Crit Care Med 1995;152:381-4.

64. Panza JA, Quyyumi AA, Brush JE Jr., Epstein SE. Abnormal endothelium-dependent vascular relaxation in patients with essential hypertension. N Engl J Med 1990;323:22-7.

65. Flammer AJ, Sudano I, Hermann F, Gay S, Forster A, Neidhart M, et al. Angiotensin-converting enzyme inhibition improves vascular function in rheumatoid arthritis. Circulation 2008;117:2262-9.

66. Sorensen KE, Celermajer DS, Georgakopoulos D, Hatcher G, Betteridge DJ, Deanfield JE. Impairment of endothelium-dependent dilation is an early event in children with familial hypercholesterolemia and is related to the lipoprotein (a) level. J Clin Invest 1994;93:50-5.

67. Charakida M, Donald AE, Terese M, Leary S, Halcox JP, Ness A, et al. Endothelial dysfunction in childhood infection. Circulation 2005;111:1660-5.

68. Flammer AJ, Anderson T, Celermajer DS, Creager MA, Deanfield J, Ganz P, et al. The assessment of endothelial function: From research into clinical practice. Circulation 2012;126:753-67.

69. Paradisi G, Steinberg HO, Hempfling A, Cronin J, Hook G, Shepard MK, et al. Polycystic ovary syndrome is associated with endothelial dysfunction. Circulation 2001;103:1410-5.

70. Diamanti-Kandarakis E, Alexandraki K, Protogerou A, Piperi C, Papamichael C, Aessopos A, et al. Metformin administration improves endothelial function in women with polycystic ovary syndrome. Eur J Endocrinol 2005;152:749-56.

71. Kravariti M, Naka KK, Kalantaridou SN, Kazakos N, Katsouras CS, Makrigiannakis A, et al. Predictors of endothelial dysfunction in young women with polycystic ovary syndrome. J Clin Endocrinol Metab 2005;90:5088-95.

72. Orio FJr., Palomba S, Cascella T, De Simone B, Manguso F, Savastano S, et al. Improvement in endothelial structure and function after metformin treatment in young normal-weight women with polycystic ovary syndrome: Results of a 6-month study. J Clin Endocrinol Metab 2005;90:6072-6.

73. Carmina E, Orio F, Palomba S, Longo RA, Cascella T, Colao A, et al. Endothelial dysfunction in PCOS: Role of obesity and adipose hormones. Am J Med 2006;119:356.e1-6.

74. Diamanti-Kandarakis E, Alexandraki K, Piperi C, Protogerou A, Katsikis I, Paterakis T, et al. Inflammatory and endothelial markers in women with polycystic ovary syndrome. Eur J Clin Invest 2006;36:691-7.

75. Diamanti-Kandarakis E, Paterakis T, Alexandraki K, Piperi C, Aessopos A, Katsikis I, et al. Indices of low-grade chronic inflammation in polycystic ovary syndrome and the beneficial effect of metformin. Hum Reprod 2006;21:1426-31.

76. Carmassi F, De Negri F, Fioriti R, De Giorgi A, Giannarelli C, Fruzzetti $\mathrm{F}$, et al. Insulin resistance causes impaired vasodilation and hypofibrinolysis in young women with polycystic ovary syndrome. Thromb Res 2005;116:207-14.

77. Charitidou C, Farmakiotis D, Zournatzi V, Pidonia I, Pegiou T, Karamanis N, et al. The administration of estrogens, combined with anti-androgens, has beneficial effects on the hormonal features and asymmetric dimethyl-arginine levels, in women with the polycystic ovary syndrome. Atherosclerosis 2008;196:958-65.

78. Heutling D, Schulz H, Nickel I, Kleinstein J, Kaltwasser P, Westphal S, et al. Asymmetrical dimethylarginine, inflammatory and metabolic parameters in women with polycystic ovary syndrome before and after metformin treatment. J Clin Endocrinol Metab 2008;93:82-90.

79. Ozgurtas T, Oktenli C, Dede M, Tapan S, Kenar L, Sanisoglu SY, et al. Metformin and oral contraceptive treatments reduced circulating asymmetric dimethylarginine (ADMA) levels in patients with polycystic ovary syndrome (PCOS). Atherosclerosis 2008;200:336-44.

80. Moran LJ, Hutchison SK, Meyer C, Zoungas S, Teede HJ. A comprehensive assessment of endothelial function in overweight women with and without polycystic ovary syndrome. Clin Sci (Lond) 2009;116:761-70.

81. Rajendran S, Willoughby SR, Chan WP, Liberts EA, Heresztyn T, Saha M, et al. Polycystic ovary syndrome is associated with severe platelet and endothelial dysfunction in both obese and lean subjects. Atherosclerosis 2009;204:509-14.

82. Mohamadin AM, Habib FA, Al-Saggaf AA. Cardiovascular disease markers in women with polycystic ovary syndrome with emphasis on asymmetric dimethylarginine and homocysteine. Ann Saudi Med 2010;30:278-83.

83. Teede HJ, Meyer C, Hutchison SK, Zoungas S, McGrath BP, Moran LJ. Endothelial function and insulin resistance in polycystic ovary syndrome: The effects of medical therapy. Fertil Steril 2010;93:184-91.

84. Bickerton AS, Clark N, Meeking D, Shaw KM, Crook M, Lumb P, et al. Cardiovascular risk in women with polycystic ovarian syndrome (PCOS). J Clin Pathol 2005;58:151-4.

85. Toulis KA, Goulis DG, Mintziori G, Kintiraki E, Eukarpidis E, Mouratoglou SA, et al. Meta-analysis of cardiovascular disease risk markers in women with polycystic ovary syndrome. Hum Reprod Update 2011;17:741-60.

86. Jezovnik MK, Jensterle Sever M, Janez A, Pfeifer M, Spirkoska A, Kravos NA, et al. Comparison of different methods investigating functional and morphological markers of early atherogenesis in obese women with polycystic ovary syndrome. Int Angiol 2015;35:446-54.

87. Akishita M, Hashimoto M, Ohike $\mathrm{Y}$, Ogawa $\mathrm{S}$, Iijima $\mathrm{K}$, Eto $\mathrm{M}$, et al. Low testosterone level is an independent determinant of endothelial dysfunction in men. Hypertens Res 2007;30:1029-34.

88. Empen K, Lorbeer R, Dörr M, Haring R, Nauck M, Gläser S, et al. Association of testosterone levels with endothelial function in men: Results from a population-based study. Arterioscler Thromb Vasc Biol 2012;32:481-6.

89. Yilmaz MI, Sonmez A, Qureshi AR, Saglam M, Stenvinkel P, Yaman H, et al. Endogenous testosterone, endothelial dysfunction, and cardiovascular events in men with nondialysis chronic kidney disease. Clin J Am Soc Nephrol 2011;6:1617-25.

90. Lopes RA, Neves KB, Carneiro FS, Tostes RC. Testosterone and vascular function in aging. Front Physiol 2012;3:89.

91. Brinkworth GD, Noakes M, Moran LJ, Norman R, Clifton PM. Flow-mediated dilatation in overweight and obese women with polycystic ovary syndrome. BJOG 2006;113:1308-14.

92. Sprung VS, Jones H, Pugh CJ, Aziz NF, Daousi C, Kemp GJ, et al. Endothelial dysfunction in hyperandrogenic polycystic ovary syndrome is not explained by either obesity or ectopic fat deposition. Clin Sci (Lond) 2014;126:67-74.

93. Studen KB, Sebestjen M, Pfeifer M, PrezeljJ. Influence of spironolactone treatment on endothelial function in non-obese women with polycystic ovary syndrome. Eur J Endocrinol 2011;164:389-95.

94. Anderson TJ, Meredith IT, Yeung AC, Frei B, Selwyn AP, Ganz P. The effect of cholesterol-lowering and antioxidant therapy on endothelium-dependent coronary vasomotion. N Engl J Med 1995;332:488-93.

95. Treasure CB, Klein JL, Weintraub WS, Talley JD, Stillabower ME, Kosinski AS, et al. Beneficial effects of cholesterol-lowering therapy on the coronary endothelium in patients with coronary artery disease. N Engl J Med 1995;332:481-7.

96. Sader MA, Celermajer DS. Endothelial function, vascular reactivity and gender differences in the cardiovascular system. Cardiovasc Res 2002;53:597-604.

97. Carrero JJ, Kyriazis J, Sonmez A, Tzanakis I, Qureshi AR, Stenvinkel P, et al. Prolactin levels, endothelial dysfunction, and the risk of cardiovascular events and mortality in patients with CKD. Clin J Am Soc Nephrol 2012;7:207-15.

98. Tarkun I, Arslan BC, Cantürk Z, Türemen E, Sahin T, Duman C. Endothelial dysfunction in young women with polycystic ovary 
syndrome: Relationship with insulin resistance and low-grade chronic inflammation. J Clin Endocrinol Metab 2004;89:5592-6.

99. Karakas SE, Kim K, Duleba AJ. Determinants of impaired fasting glucose versus glucose intolerance in polycystic ovary syndrome. Diabetes Care 2010;33:887-93.

100. Kocer D, Bayram F, Diri H. The effects of metformin on endothelial dysfunction, lipid metabolism and oxidative stress in women with polycystic ovary syndrome. Gynecol Endocrinol 2014;30:367-71.

101. Victor VM, Rovira-Llopis S, Bañuls C, Diaz-Morales N, Lopez-Domenech S, Escribano-López I, et al. Metformin modulates human leukocyte/endothelial cell interactions and proinflammatory cytokines in polycystic ovary syndrome patients. Atherosclerosis 2015;242:167-73.

102. Merhi Z, Mcgee EA, Buyuk E. Role of advanced glycation end-products in obesity-related ovarian dysfunction. Minerva Endocrinol 2014;39:167-74.

103. Diamanti-Kandarakis E, Katsikis I, Piperi C, Kandaraki E, Piouka A, Papavassiliou AG, et al. Increased serum advanced glycation end-products is a distinct finding in lean women with polycystic ovary syndrome (PCOS). Clin Endocrinol (Oxf) 2008;69:634-41.

104. Pertynska-Marczewska M, Diamanti-Kandarakis E, Zhang J, Merhi Z. Advanced glycation end products: A link between metabolic and endothelial dysfunction in polycystic ovary syndrome? Metabolism 2015;64:1564-73.

105. Diamanti-Kandarakis E, Piperi C, Patsouris E, Korkolopoulou P, Panidis D, Pawelczyk L, et al. Immunohistochemical localization of advanced glycation end-products (AGEs) and their receptor (RAGE) in polycystic and normal ovaries. Histochem Cell Biol 2007;127:581-9.

106. Lambert EA, Teede H, Sari CI, Jona E, Shorakae S, Woodington K, et al. Sympathetic activation and endothelial dysfunction in polycystic ovary syndrome are not explained by either obesity or insulin resistance. Clin Endocrinol (Oxf) 2015;83:812-9.
107. Mather KJ, Verma S, Corenblum B, Anderson TJ. Normal endothelial function despite insulin resistance in healthy women with the polycystic ovary syndrome. J Clin Endocrinol Metab 2000;85:1851-6.

108. Yavuz Taslipinar M, Kiliç N, Bayraktar N, Güler I, Gülcan Kurt Y, Göktas T, et al. Endothelial dysfunction and insulin resistance in young women with polycystic ovarian syndrome. Turk J Med Sci 2014;44:787-91.

109. Rhee SS, Pearce EN. Update: Systemic diseases and the cardiovascular system (II). The endocrine system and the heart: A review. Rev Esp Cardiol 2011;64:220-31.

110. Lerner DJ, Kannel WB. Patterns of coronary heart disease morbidity and mortality in the sexes: A 26-year follow-up of the Framingham population. Am Heart J 1986;111:383-90.

111. Colditz GA, Willett WC, Stampfer MJ, Rosner B, Speizer FE, Hennekens $\mathrm{CH}$. Menopause and the risk of coronary heart disease in women. N Engl J Med 1987;316:1105-10.

112. Lieberman EH, Gerhard MD, Uehata A, Walsh BW, Selwyn AP, Ganz P, et al. Estrogen improves endothelium-dependent, flow-mediated vasodilation in postmenopausal women. Ann Intern Med 1994;121:936-41.

113. Spritzer PM, Maturana MA, Farias A, Bittencourt PH Jr. Nitric oxide levels and hyperinsulinemia in postmenopausal women: Relationship with hormonal, metabolic and anthropometric measurements. Recent Research in Gynecological Endocrinology. New York: Parthenon; 2001. p. 185-8.

114. Torgrimson BN, Meendering JR, Kaplan PF, Minson CT. Depot-medroxyprogesterone acetate and endothelial function before and after acute oral, vaginal, and transdermal estradiol treatment. Hypertension 2011;57:819-24.

115. Rasouli N, Kern PA. Adipocytokines and the metabolic complications of obesity. J Clin Endocrinol Metab 2008;93 11 Suppl 1:S64-73.

116. Ozegowska KE, Pawelczyk LA. The role of insulin and selected adipocytokines in patients with polycystic ovary syndrome (PCOS) - A literature review. Ginekol Pol 2015;86:300-4. 